\title{
More important than the impact factor
}

\author{
Erwin Krauskopf, PhD ${ }^{\mathrm{a}, \mathrm{b}}$ \\ a Facultad de Ciencias Biologicas, Universidad Andres Bello, Santiago, Chile \\ b Fundacion Ciencia \& Vida, Santiago, Chile
}

Received Oct 24, 2017; accepted Oct 24, 2017

doi: 10.1007/s12350-017-1117-3

The recently published editorial ${ }^{1}$ about JNC's impact factor undeniably shows a positive trend in the quality of the published items. Obviously, a journal with a high impact factor will attract more submissions as it is considered more prestigious. However, I believe that JNC should highlight other features that are rarely mentioned while assessing the quality of a journal. For instance, what journals are using the papers published by JNC? From what institutions are the researchers that cite JNC's papers?

Using the data to establish the 2016 impact factor (items published by JNC during 2014-2015), I sorted the citing journals by the total number of articles cited and established to what quartile each of them belonged to. Based on impact factor data, each journal is sorted in each of its subject categories, generating what is commonly known as quartile rankings. Therefore, Q1 represents the top $25 \%$ of the impact factor distribution for a specific subject category, Q2 between top 25\% and $50 \%$, Q3 between top 50\% and 75\%, and Q4 denotes the bottom $25 \%$ of the list. For JNC, eight out of the top ten citing journals belong to Q1, confirming the quality of the research being published by JNC. A further assessment into the affiliations registered by the authors who published their research in JNC revealed that the top five institutional contributors were Harvard Medical School, followed by Brigham and Women's Hospital, Massachusetts General Hospital, VA Medical Center, and John Hopkins University.

Another important attribute to consider is the internationality of the journal. The country that contributed the most was the United States (37.5\%), followed by Germany (7.9\%), the United Kingdom (7.9\%), Italy $(7.7 \%)$, and the Netherlands $(7.2 \%)$. This information is relevant to researchers interested in communicating their results to a wider audience.

Perhaps, it is time to emphasize some of these metrics instead of the impact factor.

\section{Reference}

1. Iskandrian AE. Impact and impact factor. J Nucl Cardiol 2017;24:1501.
Reprint requests: Erwin Krauskopf, $\mathrm{PhD}$, Facultad de Ciencias Biologicas,

Universidad Andres Bello, Santiago, Chile; erwin.krauskopf@unab.cl

J Nucl Cardiol 2018;25:346.

$1071-3581 / \$ 34.00$

Copyright (c) 2017 American Society of Nuclear Cardiology. 